\title{
Compartmentalisation of RAC1 Signalling
}

DOI:

10.1016/j.ceb.2018.04.009

\section{Document Version}

Accepted author manuscript

Link to publication record in Manchester Research Explorer

\section{Citation for published version (APA):}

Boben Payapilly, A., \& Malliri, A. (2018). Compartmentalisation of RAC1 Signalling. Current opinion in cell biology, 54, 50-56. https://doi.org/10.1016/j.ceb.2018.04.009

\section{Published in:}

Current opinion in cell biology

\section{Citing this paper}

Please note that where the full-text provided on Manchester Research Explorer is the Author Accepted Manuscript or Proof version this may differ from the final Published version. If citing, it is advised that you check and use the publisher's definitive version.

\section{General rights}

Copyright and moral rights for the publications made accessible in the Research Explorer are retained by the authors and/or other copyright owners and it is a condition of accessing publications that users recognise and abide by the legal requirements associated with these rights.

\section{Takedown policy}

If you believe that this document breaches copyright please refer to the University of Manchester's Takedown Procedures [http://man.ac.uk/04Y6Bo] or contact uml.scholarlycommunications@manchester.ac.uk providing relevant details, so we can investigate your claim.

\section{OPEN ACCESS}




\section{Compartmentalisation of RAC1 Signalling}

Aishwarya Payapilly and Angeliki Malliri

Cell Signalling Group, Cancer Research UK Manchester Institute, The University of Manchester, Alderley Park, SK10 4TG, UK

Correspondence: Angeliki.Malliri@cruk.manchester.ac.uk 


\section{Abstract}

RAC1 signalling has been implicated in a variety of dynamic cell biological processes that are orchestrated through regulated localisation and activation of RAC1. As a small GTPase, RAC1 switches between active and inactive states at various subcellular locations that include the plasma membrane, nucleus and mitochondria. Once activated, RAC1 interacts with a range of effectors that then mediate various biological functions. RAC1 is regulated by a large number of proteins that can promote its recruitment, activation, deactivation, or stability. RAC1 and its regulators are subject to various posttranslational modifications that further fine tune RAC1 localisation, levels and activity. Developments in technologies have enabled the accurate detection of activated RAC1 during processes such as cell migration, invasion and DNA damage. Here, we highlight recent advances in our understanding of RAC1 regulation and function at specific subcellular sites. 


\section{Introduction}

Small GTPases are molecular switches, alternating between active GTP-bound and inactive GDP-bound states, that function to modulate almost every aspect of cell biology through a series of complex and dynamic biochemical signalling networks [1]. Large, multi-domain proteins called guanine nucleotide exchange factors (GEFs) activate small GTPases by promoting the release of GDP thus enabling GTP binding, whilst another class of proteins, the GTPase activating proteins (GAPs) inactivate small GTPases by enabling GTP hydrolysis [2]. In addition to GEFs and GAPs, guanine nucleotide dissociation inhibitors (GDIs) also regulate small GTPases by sequestering them away from activation by GEFs, and can additionally protect them from proteasomal degradation [2]. Once in the GTP-bound conformation, small GTPases bind a range of effectors, initiating downstream signalling cascades. In this review, we primarily focus on the regulation of the small GTPase RAC1.

RAC1 was first described to promote phagocytosis via NADPH activation and superoxide production [3] and growth factor-induced membrane ruffle formation via actin polymeristaion [4]. Since then RAC1 has been found to be involved in a variety of cellular processes such as cell-cell or cell-substrate adhesion, apicobasal polarity, migration, invasion, proliferation, transcription, vesicle formation, and apoptosis [1,5-7]. The ability of RAC1 to perform these functions is dependent on its tight spatio-temporal regulation. Therefore, multiple and separate pools of RAC1 present within the same cell might orchestrate different cellular processes. In the following sections, we summarise known targeting mechanisms, biochemical regulatory events and functions of RAC1 at distinct subcellular sites and highlight the impact of compartmentalised signalling on the versatility of RAC1 function.

\section{Plasma membrane and cytoplasm}

Since it was initially shown that RAC1 regulates plasma membrane-associated processes such as phagocytosis [3], lamellipodia formation and membrane ruffling [4,8], focal contact formation [8] and E-cadherin-mediated cell-to-cell contacts [9], several discoveries have been made regarding the recruitment of RAC1 to and its regulation at the plasma membrane. 
Hydrophilic RAC1 does not possess a transmembrane domain therefore plasma membrane targeting is achieved, in part, via post-translational lipid covalent modification, i.e. geranylgeranylation of the cysteine-189 of the CLLL sequence at the extreme C-terminus of RAC1 [10]. This is followed by cleavage of the C-terminal tripeptide LLL, and carboxyl methylation, to increase its hydrophobicity [10]. Adjacent to the C-terminal CLLL sequence, the hypervariable polybasic and proline-rich regions are also required for RAC1 plasma membrane localisation [10]. Indeed, negatively charged phosphatidylinositol 4,5-bisphospate (PI(4,5)P2, PIP2) and phosphatidylinositol 3,4,5-triphosphate (PI(3,4,5)P3), PIP3) plasma membrane lipid molecules promote plasma membrane targeting of small GTPases by interacting with their positively charged polybasic sequence [11]. Interaction of RAC1 with PIP3 at the plasma membrane is required for its localisation at the leading edge of migrating cells [12]. The polybasic region in RAC1 is also known to preferentially bind phosphatidylserine [13]. Moreover, clustering of RAC1 at the plasma membrane, via its polybasic sequence, may lead to increased protein-protein interactions or changes in protein conformation [14]. Indeed, a recent study confirmed that RAC1 forms nanoclusters of 50-100 molecules at the plasma membrane of migrating fibroblasts and that the polybasic region is sufficient for nanoclustering [15]••. This study also showed that RAC1 nanoclusters are increased upon RAC1 activation and through interaction with GEFs, GAPs and effectors [15].

RAC1 can also be targeted to the plasma membrane via interaction with membranelocalised GEFs, adhesion molecules, and receptor tyrosine kinases (RTKs) and scaffold proteins [16]. For example, the transmembrane protein LGR5, expressed in adult intestinal crypt cells and colon cancer cells, recruits IQGAP together with RAC1 to the plasma membrane and thereby increases levels of cortical F-actin and enhances cell-cell adhesion [17].

Post-translational, geranylgeranyl lipid-modified RAC1 is often held in its inactive, GDPbound form in the cytoplasm by RhoGDIs. However, extracellular and intracellular signals enable RhoGDI dissociation and promote RAC1 membrane targeting and activation [18]. In addition to the geranylgeranyl type of prenylation, RAC1 also undergoes reversible palmitoylation at cysteine-178, which stabilises RAC1 at actin cytoskeleton-linked membrane regions, to enable functional membrane dynamics during spreading and migration [19]. 
Advances in microscopy techniques such as Fluorescence Resonance Energy Transfer (FRET), has enabled the simultaneous assessment of localisation and activation of RhoGTPases in real-time in living cells [20]. This has refined our understanding of RAC1 function during lamellipodia formation and migration. FRET-based studies indicated that active RAC1 forms a broad gradient just behind a narrow region of active RHOA that is located at the leading edge of migrating fibroblasts [21,22]. Active RAC1 antagonises RHOA activity and by restricting RHOA activity to the leading edge reinforces newly formed protrusions [22]. FRET-based studies have also shed light on the role of RAC1 during various cellular processes that involve changes in plasma membrane dynamics. For example, the use of a single-chain RAC1 FRET biosensor showed that increased RAC1 activity is required for invadopodia disassembly in invading tumour cells [23]. Another FRET-based study found that RAC1-activity peaked immediately before membrane closure during macropinocytosis, the formation of endocytic vesicles during plasma membrane ruffling [24]. Reversible photo-switching of RAC1 together with FRET imaging of RAC1 activity, during receptor-mediated phagocytosis of erythrocytes, demonstrated that RAC1 ON and OFF states are required for lamellipodial extension and cup-constriction respectively [25]•. Super resolution microscopy and live-cell imaging FRET-based biosensors for RAC1 also demonstrated that the activity and differential localisation of RAC1 is required for the formation of macrophage tunnelling nanotubes (TNTs), which are membranous channels that connect cells to enable the transfer of signalling material that can include vesicles and organelles [26]••. Finally, FRET-based conformational changes demonstrated that constitutively active RAC1 together with CDC42 in exosomal multivesicular endosomes (MVEs) are required for the formation of actin filaments during cargo sorting into intralumenal vesicles of MVEs [27]•. In conclusion, membrane localisation of RAC1 is regulated via its intrinsic biochemical properties that enable interaction with phospholipids and various membrane-attached proteins, which may in turn serve to positively or negatively regulate RAC1 activity and levels during various cellular processes involving changes in plasma membrane structure and function.

\section{Nucleus}

Most studied RAC1 functions are mediated at or around the plasma membrane. However, RAC1 activity was recently demonstrated at the outer envelope of the nuclear membrane, stimulated by the RAC1 GEF, STEF/TIAM2, where it regulates the formation 
or assembly of apical actin filaments required to orientate the nucleus during migration [28]. Furthermore, several studies have identified the presence of nuclear RAC1 and described the mechanisms promoting nuclear localisation of RAC1 and its functional implications. For example, nuclear localisation signals identified in the C-terminal polybasic region of RAC1 were shown to promote its nuclear accumulation [29]. Nuclear localisation of RAC1 is cell cycle-dependent, with increased nuclear localisation during late G2 phase and nuclear exclusion during early G1 [30]. RAC1 is also found to localise to centrosomes during G2, prophase and early prometaphase where it regulates centrosome separation and mitotic entry [31,32]. Additionally, nuclear import of bacterial toxin-activated RAC1 is mediated by its direct interaction with nuclear import receptor karyopherin alpha2 (KPNA2) [33]. Phosphorylation of threonine-108 in RAC1 by activated ERK, upon epidermal growth factor (EGF) treatment, also leads to increased nuclear RAC1 [34]. Furthermore, spatiotemporal resolution of fluorescence lifetime imaging microscopy (FLIM)-FRET demonstrated that DNA damage induced active, monomeric RAC1 segregation into the nucleus from inactive, dimeric RAC1 in the cytoplasm [35].

Various nuclear RAC1 functions have been identified. For example, RAC1 directly interacts with nuclear proteins such as the transcription factor STAT3 to regulate its activity by promoting its phosphorylation [36] and with BCA3 to promote nuclear NF-kB signalling [37]. Moreover, nuclear RAC1 directly interacts with nucleophosmin 1 (NPM1), that limits the GTP-loading of RAC1 and reduces cell spreading [38]. The interaction of RAC1 with NPM1 was also recently confirmed via a mass spectrometry screen [39]••. In this study it was demonstrated that RAC1 localises to both nucleus and nucleolus and that NPM1 acts as a chaperone to promote the nuclear export of RAC1. The authors detected two functional nuclear export signals (NES) in RAC1. Mutation of the NES sequences increased RAC1 nuclear accumulation, resulting in altered lamin A/C and emerin localisation, nuclear morphology deformation and increased invasiveness [39]. Besides acting as a RAC1 chaperone, NPM1 also forms a nuclear protein complex with RAC1, its GEF, ECT2, and the nucleolar transcription factor, upstream binding factor 1 (UBF1), to promote ribosomal DNA transcription essential for KRAS-Trp53induced lung tumorigenesis [40]••. Recently, TIAM1, another RAC1 GEF, has also been found to negatively regulate YAP/TAZ transcriptional activity in the nucleus of colorectal cancer cells suppressing their invasiveness [41]•. Moreover, RAC1 nuclear accumulation in complex with $\beta$-catenin occurs following Wnt or RAC1 activation, resulting in RAC1-dependent phosphorylation of $\beta$-catenin on serines 161 and 605, 
promoting the formation of nuclear $\beta$-catenin- lymphoid enhancer factor (LEF-1) complexes, necessary for transactivation of Wnt-dependent genes [42]. Identification of these various nuclear RAC1 functions and the mechanistic implications of nuclear import and export sequences in RAC1, will undoubtedly expand our understanding of RAC1 signalling.

\section{Mitochondria}

The mitochondrial localisation of RAC1 is the most recent and novel subcellular localisation of RAC1. Mitochondrial membrane localisation of RAC1 was first discovered through the interaction of RAC1 with BCL2 in BCL2-overexpressing B-cell lymphoma cells [43]. This interaction stabilises the anti-apoptotic, BCL2-mediated superoxide production required to maintain a mild pro-oxidant intracellular milieu. The role of RAC1 in superoxide production through NADPH oxidase activation is well documented [7]. Inhibiting the BCL2-RAC1 interaction or blocking superoxide production, decreased mitochondrial $\mathrm{O}_{2}^{-}$levels and sensitised lymphoma cells to apoptosis [43]. In support of this finding, formation of a mitochondrial membrane complex between RAC1, sigma-1 receptor (Sig1 R), 1,4,5-triphosphate receptor and BCL2, also regulates neuroplasticity and prevents apoptosis and autophagy by maintaining mild oxidative stress [44]. Interestingly, in contrast, loss of mitochondrial RAC1-mediated superoxide production promoted cell survival under certain conditions. For example, the inhibition of RAC1BCL2 complex formation in the mitochondria, by siRNA-mediated RAC1 reduction, had a protective effect in both an in vivo cerebral ischaemic reperfusion injury rat model and neurotoxicity induced by high glucose in PC-12 cells [45]. Inhibition of RAC1 activity also protected retinal bovine cells exposed to high glucose from ROS production, mitochondrial DNA damage and apoptosis [46]. Therefore, mitochondrial RAC1mediated superoxide production can have either cyto-protective or cytotoxic effects, depending on cell type and environmental conditions such as glucose levels.

Other mitochondrial functions of RAC1 include its contribution to the formation of pulmonary fibrosis that occurs due to increased $\mathrm{H}_{2} \mathrm{O}_{2}$ production in alveolar macrophages dependent on the direct transfer of an electron to Cys-178 of RAC1 from cytochrome c [47]. The same study also showed that Cys-189 of RAC1 was required for its mitochondrial import. Activation of mitochondrial STAT3 by BCL2 is also dependent on RAC1-GTP-induced superoxide production [48]. Therefore, with the establishment of the mitochondrial localisation of RAC1, several studies now link this localisation to 
inhibition or promotion of cytotoxicity and to pathologies. Future characterisation of the mechanisms that lead to the mitochondrial localisation of RAC1 and the molecular pathways by which mitochondrial RAC1 regulates survival would help define its impact on various diseases.

\section{Localisation of GEFs and GAPs as a mode of regulation}

The $\sim 20$ members of the Rho-GTPase family are greatly outnumbered by their regulators, with $\sim 80$ mammalian GEFs and $\sim 70$ mammalian GAPs [2]. RAC1 alone can be activated by over 30 different GEFs and inactivated by several GAPs. This large number of regulators spatially and temporally coordinates the molecular switching of Rho-GTPases. Moreover, besides activating Rho molecules, GEF proteins control the repertoire of effector proteins they interact with. Thus, the RAC1 GEF, PREX1, functions as a scaffold to enhance the interaction of active RAC1 with a distinct group of effectors, such as FLII, an actin remodelling protein, thereby regulating cell contraction and migration [49].

Most GEFs possess lipid-binding domains, such as pleckstrin homology (PH) and dock homology region-1 (DHR-1) domains with varying affinities for phosphoinositides, such as PIP2 and PIP3 [50], which promote the membrane targeting of GEFs. BinAmphiphysin-Rvs (BAR) domains in GEFs and GAPs can also target the proteins to the plasma membrane based on specific membrane curvature [51]. Localisation of the FBAR domain containing RhoGAP protein, srGAP2, to contact protrusions is required to halt extensions during contact inhibition of locomotion by inhibiting RAC1 at these specific regions [52]. The GEF, TRIO, primarily acts as a scaffold to recruit and anchor RAC1 along the surface of cells facing flow, promoting endothelial cell alignment [53]•.

GEF localisation in response to various extracellular and intracellular stimuli can result in recruitment and complex formation of Rho-GTPases and their effectors at specific subcellular sites. In particular, activation of RTK by growth factors or ligands can contribute to the spatio-temporal regulation of RAC1 activity through recruitment or phosphorylation of various GEFs. EGFR signalling in lung adenocarcinoma promotes accumulation of the RAC1-specific GEF TIAM1 through phosphorylation by AKT that promotes its interaction with the 14-3-3 scaffold protein, leading to increased TIAM1 stability [54]• Consequently, increased TIAM1 stability promotes RAC1-mediated tumorigenesis [54]. Additionally, HGF-induced accumulation of the functional complex 
between the CDC42/RAC1-specific GEF, Asef, and IQGAP1 at the cell cortex is essential for endothelial cell barrier function through RAC1 activation, leading to reorganisation of cortical actin filaments by the interaction of IQGAP1 with Arp3 and cortactin [55]. Plasma membrane lipid PIP3 and G $\beta \gamma$ are secondary messengers generated downstream of RTK and G-protein couple receptor (GPCR) activation respectively, and can interact with and activate GEFs such as PREX1 [56], PREX2 [57], VAV and SOS1 [58,59] to subsequently induce RAC1 activity.

Recruitment of GEFs such as $\beta$ PIX, DOCK180, TRIO, VAV1, VAV3, and TIAM1 to nascent focal adhesions occurs due to the interaction of GEFs with components of the adhesion complex formed in response to integrin clustering [60]. The recruitment of the DOCK1 GEF by ELMO to cell-cell adhesion sites in MDCKII cells is required for establishment of strong cell-cell adhesions through localised RAC1 activity, actin remodelling and Ecadherin spreading [61]. Conversely, DOCK5 recruitment to focal adhesions is inhibited by GIT2. Depletion of GIT2 or inhibition of GIT2 focal adhesion targeting leads to recruitment and interaction of DOCK5 with Crk at membrane protrusions and nascent focal adhesions promoting activation of the Crk-p130Cas pathway, RAC1-mediated lamellipodial extensions and focal adhesion turnover [62]•

GEFs and GAPs can also form regulatory complexes themselves, to precisely modulate Rho-GTPase activity [18]. Specifically, the modulation of RAC1 activity during excitatory synaptogenesis is achieved by the complex formation between the RAC-GAP, BCR with the RAC-GEF TIAM1 at synapses [63]. BCR inactivates TIAM1-activated RAC1 by promoting GTP to GDP hydrolysis of active, GTP-bound RAC1, thus preventing excessive synaptic growth [63]. Additionally, TIAM1 and BCR activities can be co-ordinately regulated by the EphB receptor during excitatory synaptogenesis, most likely via promoting TIAM1 phosphorylation/ GEF activation and BCR dephosphorylation/ GAP inactivation [63]. Therefore, a balance between the opposing activities of TIAM1 and $\mathrm{BCR}$, achieved via their interactions, is essential for normal dendritic spine formation.

Spatially restricted control of RAC1 activity can also be modulated through regulation of GEF abundance. TIAM1 is degraded at cell-cell junctions following ubiquitylation by HUWE1 in response to HGF stimulation and following its phosphorylation by Src. This loss of TIAM1 specifically from cell-cell adhesions facilitates cell-cell junction destabilisation, leading to increased migration and invasion [64,65]. TIAM1 could also be degraded by the Skp Cullin F-box-containing $\beta$-TrCP ubiquitin ligase, following its phosphorylation by casein kinase-1 [66]. Therefore, the localisation and regulation of 
RAC1-interacting proteins contributes an additional level of complexity to the modulation of RAC1 function.

\section{Conclusions}

While significant progress has been made in uncovering the mechanisms of RAC1 function and regulation at various subcellular sites, there is a need to integrate these various signalling modules to better understand the role of RAC in cellular function as a whole. Indeed RAC1 deregulation and dysfunction is implicated in a variety of diseases, including atherosclerosis, diabetes and cancer [67]. The knowledge of how different subcellular pools of RAC1 impact its function will enable the design of chemical inhibitors or regulators that can inhibit or enhance specific RAC1 functions, as required.

\section{Conflict of interest}

The authors declare that there are no conflicts of interest.

\section{Acknowledgements}

Research in the laboratory of Dr Angeliki Malliri is supported by Cancer Research UK (grant number C5759/A12328) and Worldwide Cancer Research (grant number WCR 16-0379).

\section{References}

1. Jaffe AB, Hall A: Rho gtpases: Biochemistry and biology. Annual Review of Cell and Developmental Biology (2005) 21(1):247-269.

2. Cherfils J, Zeghouf M: Regulation of small gtpases by gefs, gaps, and gdis. Physiological reviews (2013) 93(1):269-309.

3. Abo A, Pick E, Hall A, Totty N, Teahan CG, Segal AW: Activation of the nadph oxidase involves the small gtp-binding protein p21rac1. Nature (1991) 353(6345):668-670. 
4. Ridley AJ, Paterson HF, Johnston CL, Diekmann D, Hall A: The small gtp-binding protein rac regulates growth factor-induced membrane ruffling. Cell (1992) 70(3):401-410.

5. Bosco EE, Mulloy JC, Zheng Y: Rac1 gtpase: A "rac" of all trades. Cellular and Molecular Life Sciences (2008) 66(3):370.

6. Biro M, Munoz MA, Weninger W: Targeting rho-gtpases in immune cell migration and inflammation. British journal of pharmacology (2014) 171(24):5491-5506.

7. Chong SJF, Lai JXH, Eu JQ, Bellot G, Pervaiz S: Reactive oxygen species and oncoprotein signaling-a dangerous liaison. Antioxidants \& Redox Signaling (2017).

8. Nobes CD, Hall A: Rho, rac, and cdc42 gtpases regulate the assembly of multimolecular focal complexes associated with actin stress fibers, lamellipodia, and filopodia. Cell (1995) 81(1):53-62.

9. Braga VMM, Machesky LM, Hall A, Hotchin NA: The small gtpases rho and rac are required for the establishment of cadherin-dependent cell-cell contacts. The Journal of cell biology (1997) 137(6):1421.

10. Bustelo XR, Ojeda V, Barreira M, Sauzeau V, Castro-Castro A: Rac-ing to the plasma membrane: The long and complex work commute of rac1 during cell signaling. Small GTPases (2012) 3(1):60-66.

11. Heo WD, Inoue T, Park WS, Kim ML, Park BO, Wandless TJ, Meyer T: Pi(3,4,5)p3 and pi(4,5)p2 lipids target proteins with polybasic clusters to the plasma membrane. Science (2006) 314(5804):1458-1461.

12. Das S, Yin T, Yang Q, Zhang J, Wu YI, Yu J: Single-molecule tracking of small gtpase rac1 uncovers spatial regulation of membrane translocation and mechanism for polarized signaling. Proceedings of the National Academy of Sciences of the United States of America (2015) 112(3):E267-276.

13. Finkielstein CV, Overduin M, Capelluto DG: Cell migration and signaling specificity is determined by the phosphatidylserine recognition motif of rac1. J Biol Chem (2006) 281(37):27317-27326.

14. Li L, Shi X, Guo X, Li H, Xu C: Ionic protein-lipid interaction at the plasma membrane: What can the charge do? Trends in biochemical sciences (2014) 39(3):130-140. 
15. Remorino A, De Beco S, Cayrac F, Di Federico F, Cornilleau G, Gautreau A, Parrini MC, Masson JB, Dahan M, Coppey M: Gradients of rac1 nanoclusters support spatial patterns of rac1 signaling. Cell Rep (2017) 21(7):1922-1935.

16. Fritz RD, Pertz O: The dynamics of spatio-temporal rho gtpase signaling: Formation of signaling patterns. F1000Research (2016) 5(F1000 Faculty Rev1749.

17. Carmon KS, Gong X, Yi J, Wu L, Thomas A, Moore CM, Masuho I, Timson DJ, Martemyanov KA, Liu QJ: Lgr5 receptor promotes cell-cell adhesion in stem cells and colon cancer cells via the iqgap1-rac1 pathway. J Biol Chem (2017) 292(36):14989-15001.

18. Hodge RG, Ridley AJ: Regulating rho gtpases and their regulators. Nature Reviews Molecular Cell Biology (2016) 17(496.

19. Navarro-Lerida I, Sanchez-Perales S, Calvo M, Rentero C, Zheng Y, Enrich C, Del Pozo MA: A palmitoylation switch mechanism regulates rac1 function and membrane organization. The EMBO journal(2012) 31(3):534-551.

20. Donnelly SK, Bravo-Cordero JJ, Hodgson L: Rho gtpase isoforms in cell motility: Don't fret, we have fret. Cell Adhesion \& Migration (2014) 8(6):526-534.

21. Itoh RE, Kurokawa K, Ohba Y, Yoshizaki H, Mochizuki N, Matsuda M: Activation of rac and cdc42 video imaged by fluorescent resonance energy transfer-based single-molecule probes in the membrane of living cells. Mol Cell Biol (2002) 22(18):6582-6591.

22. Machacek M, Hodgson L, Welch C, Elliott H, Pertz O, Nalbant P, Abell A, Johnson GL, Hahn KM, Danuser G: Coordination of rho gtpase activities during cell protrusion. Nature (2009) 461(7260):99-103.

23. Moshfegh Y, Bravo-Cordero JJ, Miskolci V, Condeelis J, Hodgson L: A trio-rac1pak1 signaling axis drives invadopodia disassembly. Nature cell biology(2014) 16(6):574-586.

24. Yoshida S, Hoppe AD, Araki N, Swanson JA: Sequential signaling in plasmamembrane domains during macropinosome formation in macrophages. Journal of cell science (2009) 122(Pt 18):3250-3261.

25. Ikeda Y, Kawai K, Ikawa A, Kawamoto K, Egami Y, Araki N: Rac1 switching at the right time and location is essential for fcgamma receptor-mediated phagosome formation. Journal of cell science (2017) 130(15):2530-2540. 
26. Hanna SJ, McCoy-Simandle K, Miskolci V, Guo P, Cammer M, Hodgson L, Cox D: The role of rho-gtpases and actin polymerization during macrophage tunneling nanotube biogenesis. Scientific reports (2017) 7(1):8547.

27. Kajimoto T, Mohamed NNI, Badawy SMM, Matovelo SA, Hirase M, Nakamura S, Yoshida D, Okada T, Ijuin T, Nakamura S-i: Involvement of $g \beta \gamma$ subunits of gi protein coupled with $\mathrm{s} 1 \mathrm{p}$ receptor on multivesicular endosomes in $\mathrm{f}$-actin formation and cargo sorting into exosomes. Journal of Biological Chemistry (2018) 293(1):245-253.

28. Woroniuk A, Porter A, White G, Newman D, Diamantopoulou Z, Waring T, Rooney C, Strathdee D, Marston DJ, Hahn KM, Sansom OJ et al: Stef/tiam2 mediated rac1 activity at the nuclear envelope regulates the perinuclear actin cap Nature communications (2018) In Press.

29. Lanning CC, Daddona JL, Ruiz-Velasco R, Shafer SH, Williams CL: The rac1 cterminal polybasic region regulates the nuclear localization and protein degradation of rac1. J Biol Chem (2004) 279(42):44197-44210.

30. Michaelson D, Abidi W, Guardavaccaro D, Zhou M, Ahearn I, Pagano M, Philips MR: Rac1 accumulates in the nucleus during the g2 phase of the cell cycle and promotes cell division. The Journal of cell biology (2008) 181(3):485-496.

31. May M, Schelle I, Brakebusch C, Rottner K, Genth H: Rac1-dependent recruitment of pak2 to $\mathrm{g}(2)$ phase centrosomes and their roles in the regulation of mitotic entry. Cell Cycle (2014) 13(14):2210-2220.

32. Woodcock SA, Rushton HJ, Castaneda-Saucedo E, Myant K, White GR, Blyth K, Sansom OJ, Malliri A: Tiam1-rac signaling counteracts eg5 during bipolar spindle assembly to facilitate chromosome congression. Current biology : $C B(2010)$ 20(7):669-675.

33. Sandrock K, Bielek H, Schradi K, Schmidt G, Klugbauer N: The nuclear import of the small gtpase rac1 is mediated by the direct interaction with karyopherin alpha2. Traffic (Copenhagen, Denmark) (2010) 11(2):198-209.

34. Tong J, Li L, Ballermann B, Wang Z: Phosphorylation of rac1 t108 by extracellular signal-regulated kinase in response to epidermal growth factor: $\mathrm{A}$ novel mechanism to regulate rac1 function. Mol Cell Biol(2013) 33(22):45384551.

35. Hinde E, Yokomori K, Gaus K, Hahn KM, Gratton E: Fluctuation-based imaging of nuclear rac1 activation by protein oligomerisation. Scientific reports (2014) 4(4219.

36. Simon AR, Vikis HG, Stewart S, Fanburg BL, Cochran BH, Guan KL: Regulation of stat3 by direct binding to the rac1 gtpase. Science (2000) 290(5489):144-147. 
37. Yao C, Yu KP, Philbrick W, Sun BH, Simpson C, Zhang C, Insogna K: Breast cancerassociated gene 3 interacts with rac1 and augments nf-kappab signaling in vitro, but has no effect on rankl-induced bone resorption in vivo. International journal of molecular medicine (2017) 40(4):1067-1077.

38. Zoughlami Y, van Stalborgh AM, van Hennik PB, Hordijk PL: Nucleophosmin1 is a negative regulator of the small gtpase rac1. PloS one (2013) 8(7):e68477.

39. Navarro-Lerida I, Pellinen T, Sanchez SA, Guadamillas MC, Wang Y, Mirtti T, Calvo E, Del Pozo MA: Rac1 nucleocytoplasmic shuttling drives nuclear shape changes and tumor invasion. Developmental cell (2015) 32(3):318-334.

40. Justilien V, Ali SA, Jamieson L, Yin N, Cox AD, Der CJ, Murray NR, Fields AP: Ect2dependent rrna synthesis is required for kras-trp53-driven lung adenocarcinoma. Cancer cell (2017) 31(2):256-269.

41. Diamantopoulou Z, White G, Fadlullah MZH, Dreger M, Pickering K, Maltas J, Ashton G, MacLeod R, Baillie GS, Kouskoff V, Lacaud G et al: Tiam1 antagonizes taz/yap both in the destruction complex in the cytoplasm and in the nucleus to inhibit invasion of intestinal epithelial cells. Cancer cell (2017) 31(5):621634.e626.

42. Jamieson C, Lui C, Brocardo MG, Martino-Echarri E, Henderson BR: Rac1 augments wnt signaling by stimulating beta-catenin-lymphoid enhancer factor-1 complex assembly independent of beta-catenin nuclear import. Journal of cell science (2015) 128(21):3933-3946.

43. Velaithan R, Kang J, Hirpara JL, Loh T, Goh BC, Le Bras M, Brenner C, Clement MV, Pervaiz $S$ : The small gtpase rac1 is a novel binding partner of bcl-2 and stabilizes its antiapoptotic activity. Blood (2011) 117(23):6214-6226.

44. Natsvlishvili N, Goguadze N, Zhuravliova E, Mikeladze D: Sigma-1 receptor directly interacts with rac1-gtpase in the brain mitochondria. BMC biochemistry (2015) 16(11.

45. Pan Y, Wang N, Xia P, Wang E, Guo Q, Ye Z: Inhibition of rac1 ameliorates neuronal oxidative stress damage via reducing bcl-2/rac1 complex formation in mitochondria through pi3k/akt/mtor pathway. Experimental neurology (2018) 300(149-166.

46. Kowluru RA, Kowluru A, Veluthakal R, Mohammad G, Syed I, Santos JM, Mishra M: Tiam1-rac1 signalling axis-mediated activation of nadph oxidase-2 initiates mitochondrial damage in the development of diabetic retinopathy. Diabetologia (2014) 57(5):1047-1056. 
47. Osborn-Heaford HL, Ryan AJ, Murthy S, Racila A-M, He C, Sieren JC, Spitz DR, Carter AB: Mitochondrial rac1 gtpase import and electron transfer from cytochrome $\mathrm{c}$ are required for pulmonary fibrosis. The Journal of Biological Chemistry(2012) 287(5):3301-3312.

48. Kang J, Chong SJF, Ooi VZQ, Vali S, Kumar A, Kapoor S, Abbasi T, Hirpara JL, Loh $\mathrm{T}$, Goh BC, Pervaiz S: Overexpression of bcl-2 induces stat-3 activation via an increase in mitochondrial superoxide. Oncotarget (2015) 6(33):34191-34205.

49. Marei H, Carpy A, Woroniuk A, Vennin C, White G, Timpson P, Macek B, Malliri A: Differential rac1 signalling by guanine nucleotide exchange factors implicates flii in regulating rac1-driven cell migration. Nature communications (2016) $7(10664$.

50. Maffucci T, Falasca M: Specificity in pleckstrin homology (ph) domain membrane targeting: A role for a phosphoinositide-protein co-operative mechanism. FEBS letters (2001) 506(3):173-179.

51. Aspenstrom P: Bar domain proteins regulate rho gtpase signaling. Small GTPases (2014) 5(2):7.

52. Fritz RD, Menshykau D, Martin K, Reimann A, Pontelli V, Pertz O: Srgap2dependent integration of membrane geometry and slit-robo-repulsive cues regulates fibroblast contact inhibition of locomotion. Developmental cell (2015) 35(1):78-92.

53. Kroon J, Heemskerk N, Kalsbeek MJT, de Waard V, van Rijssel J, van Buul JD: Flow-induced endothelial cell alignment requires the rhogef trio as a scaffold protein to polarize active rac1 distribution. Molecular biology of the cell (2017) 28(13):1745-1753.

54. Zhu G, Fan Z, Ding M, Zhang H, Mu L, Ding Y, Zhang Y, Jia B, Chen L, Chang Z, Wu $\mathrm{W}$ : An egfr/pi3k/akt axis promotes accumulation of the rac1-gef tiam1 that is critical in egfr-driven tumorigenesis. Oncogene (2015) 34(49):5971-5982.

55. Tian Y, Gawlak G, Shah AS, Higginbotham K, Tian X, Kawasaki Y, Akiyama T, Sacks DB, Birukova AA: Hepatocyte growth factor-induced asef-iqgap1 complex controls cytoskeletal remodeling and endothelial barrier. J Biol Chem (2015) 290(7):4097-4109.

56. Welch HCE, Coadwell WJ, Ellson CD, Ferguson GJ, Andrews SR, ErdjumentBromage H, Tempst P, Hawkins PT, Stephens LR: P-rex1, a ptdins(3,4,5)p3- and $\mathrm{g} \beta \gamma$-regulated guanine-nucleotide exchange factor for rac. Cell (2002) 108(6):809-821.

57. Rosenfeldt H, Vázquez-Prado J, Gutkind JS: P-rex2, a novel pi-3-kinase sensitive rac exchange factor. FEBS letters (2004) 572(1):167-171. 
58. Han J, Luby-Phelps K, Das B, Shu X, Xia Y, Mosteller RD, Krishna UM, Falck JR, White MA, Broek D: Role of substrates and products of pi 3-kinase in regulating activation of rac-related guanosine triphosphatases by vav. Science (1998) 279(5350):558.

59. Das B, Shu X, Day G-J, Han J, Krishna UM, Falck JR, Broek D: Control of intramolecular interactions between the pleckstrin homology and dbl homology domains of vav and sos1 regulates rac binding. Journal of Biological Chemistry (2000) 275(20):15074-15081.

60. Lawson CD, Burridge K: The on-off relationship of rho and rac during integrinmediated adhesion and cell migration. Small GTPases (2014) 5(1):e27958.

61. Toret CP, Collins C, Nelson WJ: An elmo-dock complex locally controls rho gtpases and actin remodeling during cadherin-mediated adhesion. The Journal of cell biology (2014) 207(5):577-587.

62. Frank SR, Kollmann CP, van Lidth de Jeude JF, Thiagarajah JR, Engelholm LH, Frodin $\mathrm{M}$, Hansen $\mathrm{SH}$ : The focal adhesion-associated proteins dock5 and git2 comprise a rheostat in control of epithelial invasion. Oncogene (2017) 36(13):1816-1828.

63. Um K, Niu S, Duman JG, Cheng JX, Tu YK, Schwechter B, Liu F, Hiles L, Narayanan AS, Ash RT, Mulherkar S et al: Dynamic control of excitatory synapse development by a rac1 gef/gap regulatory complex. Developmental cell(2014) 29(6):701-715.

64. Woodcock SA, Rooney C, Liontos M, Connolly Y, Zoumpourlis V, Whetton AD, Gorgoulis VG, Malliri A: Src-induced disassembly of adherens junctions requires localized phosphorylation and degradation of the rac activator tiam1. Molecular cell(2009) 33(5):639-653.

65. Vaughan L, Tan CT, Chapman A, Nonaka D, Mack NA, Smith D, Booton R, Hurlstone AF, Malliri A: Huwe1 ubiquitylates and degrades the rac activator tiam1 promoting cell-cell adhesion disassembly, migration, and invasion. Cell $\operatorname{Rep}(2015)$ 10(1):88-102.

66. Magliozzi R, Kim J, Low TY, Heck AJ, Guardavaccaro D: Degradation of tiam1 by casein kinase 1 and the scfbetatrcp ubiquitin ligase controls the duration of mtor-s6k signaling. J Biol Chem (2014) 289(40):27400-27409.

67. Olson MF: Rho gtpases, their post-translational modifications, disease-associated mutations and pharmacological inhibitors. Small GTPases (2016) 1-13. 
-Diamantopoulou, Z., G. White, M. Z. H. Fadlullah, M. Dreger, K. Pickering, J. Maltas, G. Ashton, R. MacLeod, G. S. Baillie, V. Kouskoff, G. Lacaud, G. I. Murray, O. J. Sansom, A. F. L. Hurlstone and A. Malliri (2017). "TIAM1 Antagonizes TAZ/YAP Both in the Destruction Complex in the Cytoplasm and in the Nucleus to Inhibit Invasion of Intestinal Epithelial Cells." Cancer Cell 31(5): 621-634.e626.

TIAM1, a RAC1 GEF, was found to negatively regulate YAP/TAZ transcriptional activity in the nucleus of colorectal cancer cells.

-Frank, S. R., C. P. Kollmann, J. F. van Lidth de Jeude, J. R. Thiagarajah, L. H. Engelholm, M. Frodin and S. H. Hansen (2017). "The focal adhesion-associated proteins DOCK5 and GIT2 comprise a rheostat in control of epithelial invasion." Oncogene 36(13): 18161828.

GIT2 functions to negatively regulate DOCK5 recruitment to nascent focal adhesion sites and thus prevents DOCK5-mediated activation of RAC1 that is important of lamellipodial extensions and focal adhesion turnover.

••Hanna, S. J., K. McCoy-Simandle, V. Miskolci, P. Guo, M. Cammer, L. Hodgson and D. Cox (2017). "The Role of Rho-GTPases and actin polymerization during Macrophage Tunneling Nanotube Biogenesis." Sci Rep 7(1): 8547.

Use of super resolution microscopy and live-cell imaging FRET-based biosensors for RAC1 has also demonstrated that the activity and differential localisation of RAC1 was required for the formation of macrophage tunneling nanotubes.

-Ikeda, Y., K. Kawai, A. Ikawa, K. Kawamoto, Y. Egami and N. Araki (2017). "Rac1 switching at the right time and location is essential for Fcgamma receptor-mediated phagosome formation." LCell Sci 130(15): 2530-2540.

Reversible photo-switching of RAC1 together with FRET imaging of RAC1 activity has revealed that, RAC1 ON and OFF states are required for lamellipodial extension and cupconstriction, respectively during receptor-mediated phagocytosis of erythrocytes.

$\bullet-J u s t i l i e n$, V., S. A. Ali, L. Jamieson, N. Yin, A. D. Cox, C. J. Der, N. R. Murray and A. P. Fields (2017). "Ect2-Dependent rRNA Synthesis Is Required for KRAS-TRP53-Driven Lung Adenocarcinoma." Cancer Cell 31(2): 256-269.

A nuclear protein complex of RAC1, its GEF, ECT2 and the nucleolar transcription factor upstream binding factor 1 (UBF1) promoted ribosomal DNA transcription that was essential for Kras-Trp53-induced lung tumorigenesis.

-Kajimoto, T., N. N. I. Mohamed, S. M. M. Badawy, S. A. Matovelo, M. Hirase, S. Nakamura,

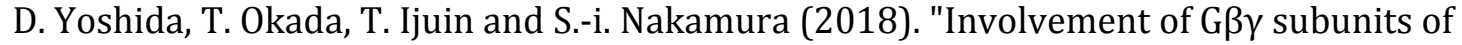
Gi protein coupled with S1P receptor on multivesicular endosomes in F-actin formation and cargo sorting into exosomes." Journal of Biological Chemistry 293(1): 245-253.

RAC1 together with CDC42 is constitutively active on exosomal multivesicular endosomes (MVEs) and is required for the formation of actin filaments during cargo sorting into intralumenal vesicles of MVEs.

-Kroon, J., N. Heemskerk, M. J. T. Kalsbeek, V. de Waard, J. van Rijssel and J. D. van Buul (2017). "Flow-induced endothelial cell alignment requires the RhoGEF Trio as a scaffold protein to polarize active Rac1 distribution." Mol Biol Cell 28(13): 1745-1753. 
The RAC1 GEF, TRIO primarily acts as a scaffold to recruit and anchor RAC1 along the surface of cells facing downstream flow, promoting endothelial cell alignment.

$\bullet$ Navarro-Lerida, I., T. Pellinen, S. A. Sanchez, M. C. Guadamillas, Y. Wang, T. Mirtti, E. Calvo and M. A. Del Pozo (2015). "Rac1 nucleocytoplasmic shuttling drives nuclear shape changes and tumor invasion." Dev Cell 32(3): 318-334.

Identified nuclear export signals in RAC1 and demonstrated that nuclear RAC1

localisation is regulated by NPM1. Aberrant increase in nuclear RAC1 was shown to promote invasiveness.

$\bullet$ Remorino, A., S. De Beco, F. Cayrac, F. Di Federico, G. Cornilleau, A. Gautreau, M. C. Parrini, J. B. Masson, M. Dahan and M. Coppey (2017). "Gradients of Rac1 Nanoclusters Support Spatial Patterns of Rac1 Signaling." Cell Rep 21(7): 1922-1935.

Nanoclustering of RAC1 at the plasma membrane leads to enhanced RAC1 activation and the recruitment of GEFs together with RAC1 effector proteins to form signalling platforms.

-Zhu, G., Z. Fan, M. Ding, H. Zhang, L. Mu, Y. Ding, Y. Zhang, B. Jia, L. Chen, Z. Chang and W. Wu (2015). "An EGFR/PI3K/AKT axis promotes accumulation of the Rac1-GEF Tiam1 that is critical in EGFR-driven tumorigenesis." Oncogene 34(49): 5971-5982.

EGFR signalling in lung adenocarcinoma was shown to promote the accumulation of the RAC1-specific GEF TIAM1 through phosphorylation of TIAM1 by AKT that promoted the interaction of TIAM1 with the 14-3-3 scaffold protein, leading to increased TIAM1 stability. 


\section{Figure Legend}

Figure 1. Compartmentalised RAC1 signalling: Summary of known subcellular RAC1 localisations or recruitments due to post-translational modifications or various biochemical interactions. (1) RAC1 is post-translationally modified at the ER. (2) RhoGDIs hold RAC1 in its inactive GTP-bound state in the cytoplasm. (3) Both and active and inactive RAC1 can form oligomers at the plasma membrane. (4) Nano-clusters of RAC1 lead to the clustering of GEFs and effector proteins. (5) During migration on an extracellular matrix, a gradient of active RAC1 is formed just behind the leading edge of the cell. (6) Activation of RTKs or GPCRs may lead to the recruitment of GEFs and result in RAC1 activation. (7) Scaffold proteins present at focal adhesions and cell-cell junctions can lead to the recruitment of GEFs and the activation of RAC1. (8) RAC1 is involved in macropinocytosis, an actin-dependent endocytic process. (9) RAC1 activity is required during maturation of MVEs. (10) At the mitochondria, RAC1 interacts with BCL2 and can also be imported into the mitochondria. (11) Active RAC1 has been detected in the nucleus. Additionally, inside the nucleus, NPM1 acts as a chaperone for RAC1 to promote its nuclear-cytoplasmic shuttling. (12) RAC1 is also present in the nucleolus and forms a complex with its GEF, ECT2, UBF1 and NPM1 to promote ribosomal DNA synthesis. (13) RAC1 localises to centrosomes and regulates centrosome separation. 


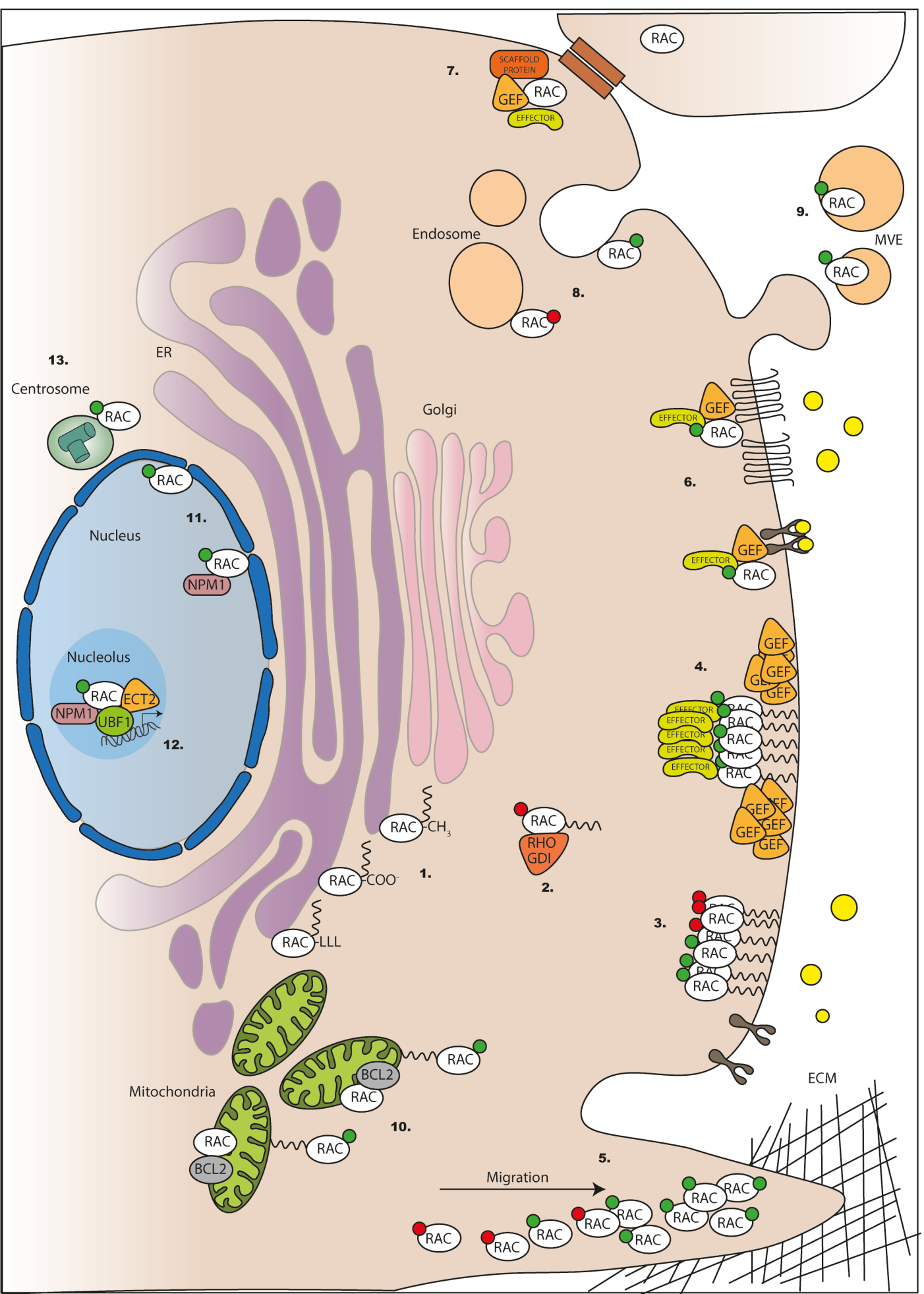

(RAC) active GTP-bound RAC1

RAC inactive GDP-bound RAC1

$\bigcirc$ extracellular ligand

m lipid modification

$\int$ receptor tyrosine kinase

JUADS GPCR receptor

ECM Extracellular matrix

MVE Multivesicular exosome

II cell-cell junctions 